\title{
Salamanders increase their feeding activity when infected with the pathogenic chytrid fungus Batrachochytrium dendrobatidis
}

\author{
Alexandra Hess* , Caroline McAllister, Joseph DeMarchi, Makenzie Zidek, \\ Julie Murone, Matthew D. Venesky ${ }^{* * *}$
}

Department of Biology, Allegheny College, Meadville, PA 16335, USA

\begin{abstract}
Immune function is a costly line of defense against parasitism. When infected with a parasite, hosts frequently lose mass due to these costs. However, some infected hosts (e.g. highly resistant individuals) can clear infections with seemingly little fitness losses, but few studies have tested how resistant hosts mitigate these costly immune defenses. We explored this topic using eastern red-backed salamanders Plethodon cinereus and the fungal pathogen Batrachochytrium dendrobatidis $(B d)$. $B d$ is generally lethal for amphibians, and stereotypical symptoms of infection include loss in mass and deficits in feeding. However, individuals of $P$. cinereus can clear their $B d$ infections with seemingly few fitness costs. We conducted an experiment in which we repeatedly observed the feeding activity of $B d$-infected and non-infected salamanders. We found that $B d$ infected salamanders generally increased their feeding activity compared to non-infected salamanders. The fact that we did not observe any differences in mass change between the treatments suggests that increased feeding might help $B d$-infected salamanders minimize the costs of an effective immune response.
\end{abstract}

KEY WORDS: Amphibian · Batrachochytrium dendrobatidis · Behavior · Chytridiomycosis Disease $\cdot$ Plethodon cinereus $\cdot$ Resistance

\section{INTRODUCTION}

The immune system is an effective line of defense against parasitism. However, the development and activation of an immune response can have substantial genetic (McKean et al. 2008) and physiological (Lochmiller \& Deerenberg 2000) costs. Because resources are often limited, theory in ecological immunology predicts that organisms face an allocation trade-off between an investment in immune function and other functions such as growth and development (Schmid-Hempel 2003), physiological capacity (Martin et al. 2008, Ardia et al. 2012), and traits associated with mating success (Hasselquist \&
Nilsson 2012). One common type of trade-off comes in the form of 'sickness behaviors' (e.g. lethargy, decreased libido, and lack of social interactions; Johnson 2002), which are thought to be adaptive behavioral responses that allow hosts to direct energy away from non-vital functions and to promote immune responsiveness. For example, male song sparrows Melospiza melodia whose immune system was activated via lipopolysaccharide injection exhibited increased lethargy and decreased territoriality during the non-breeding season compared to non-injected birds (Owen-Ashley \& Wingfield 2006), which was presumably an adaptive reallocation of energy towards immune function. 
However, lethargy associated with sickness behaviors can result in deficits that are not always adaptive with respect to the host and thus favor parasite success (Thompson et al. 2005). For instance, parasitism can decrease host feeding behavior and efficiency (Gegear et al. 2006, Venesky et al. 2009), which can cause hosts to become nutritionally deprived and thus further reduce the strength of their immune responses (Gasparini et al. 2006, Brzek \& Konarzewski 2007).

To offset some of the costs associated with activating the immune system, some parasitized hosts consume more food compared to non-infected individuals, thereby limiting the trade-offs between immune function and other physiological processes. This concept is illustrated by observations that organisms with access to high-quality food have more effective immune responses compared to those with low-quality food (Diamond \& Kingsolver 2011) and that food consumption is positively associated with immune system activity (Tyler et al. 2006). Moreover, there is evidence that infected individuals selectively choose a diet that is high in macronutrients and/or anti-parasitic compounds (de Roode et al. 2013). For example, protein synthesis and amino acid production increase significantly during immune activity (Lochmiller \& Deerenberg 2000). In support of this, Lee et al. (2008) found that a high-protein diet increased immune function in African cotton leafworms Spodoptera exempta relative to a low-protein diet. In addition, when given a choice between isocaloric diets that were rich in either protein or carbohydrates, infected individuals of $S$. exempta increased protein consumption whereas non-infected individuals did not alter their dietary choice (Povey et al. 2009).

Because food acquisition and feeding behavior have direct effects on an individual's resource pool, determining how infected hosts mitigate the costs associated with immunity has emerged as a central principle in the field of ecological immunology. Understanding how individuals or species offset the costs of immunity is of no greater importance than for amphibians, whose populations are declining rapidly on a global scale (Wake \& Vredenburg 2008). Chytridiomycosis, caused by the amphibian chytrid fungus Batrachochytrium dendrobatidis $(B d)$, is an emerging infectious disease that is associated with amphibian population declines (Rohr \& Raffel 2010). Symptoms of chytridiomycosis in amphibians generally include stereotypical sickness behaviors (e.g. lethargy and inappetence) as well as irregular skin sloughing and loss of righting reflex (Voyles et al. 2011). Despite the fact that $B d$ can cause high mortality in amphibians, some individuals and species are resistant (or tolerant) to infection (Venesky et al. 2014, Ellison et al. 2015, Rollins-Smith et al. 2015). Although $B d$ is known to evade components of the amphibian immune response (Fites et al. 2013), amphibians can deploy effective immune responses towards $B d$. The first line of innate immune defenses against $B d$ is generally thought to come from antimicrobial peptides and other skin microbiota (Voyles et al. 2011, Bletz et al. 2013). Furthermore, frogs had reduced leukocyte numbers in the spleen associated with increased $B d$ infection intensity, which suggests that an adaptive lymphocyte response contributes to the control of $B d$ skin infections (Ramsey et al. 2010). Corroborating this finding, recent evidence has demonstrated that frogs can acquire resistance to $B d$, possibly mediated through changes in lymphocyte abundance and proliferation (McMahon et al. 2014).

To explore the relationship between feeding activity and $B d$ resistance, we conducted a laboratory experiment in which we compared the feeding behavior of $B d$-infected and non-infected eastern redbacked salamanders Plethodon cinereus throughout the progression of an infection. Terrestrial plethodontid salamanders appear generally resistant to $B d$ (Muletz et al. 2014) and lack stereotypical symptoms of chytridiomycosis, and individuals of $P$. cinereus can clear $B d$ infections in laboratory conditions thought to be ideal for growth of many $B d$ isolates (Becker \& Harris 2010, Venesky et al. 2015). Because individuals of $P$. cinereus are relatively resistant to $B d$ and $B d$ resistance is presumably costly, we predicted that $B d$-infected salamanders would attack and consume more fruit flies Drosophila melanogaster than noninfected salamanders. Because the costs of immune function should be greatest when the salamanders are infected with $B d$, we also predicted that $B d$ infected salamanders would increase their feeding activity early in the experiment (when they were still infected) relative to non-infected salamanders but that the $B d$-infected and non-infected salamanders would not differ in their feeding activity late in the experiment (after the $B d$-infected salamanders cleared their infections).

\section{MATERIALS AND METHODS}

\section{Salamander collection and husbandry}

We hand-collected adult red-striped Plethodon cinereus $(\mathrm{n}=21$ in May for Expt 1; $\mathrm{n}=24$ in October 
for Expt 2) from under rocks and logs from a single location in an oak/maple forested area in Crawford County, Pennsylvania, USA. Upon collection, the salamanders were transported to a laboratory and housed individually in vented plastic containers $(75 \mathrm{~mm}$ deep, $110 \mathrm{~mm}$ diameter) on non-bleached paper towels soaked with $12 \mathrm{ml}$ of aged and de-chlorinated tap water. Throughout the experiments, we provided the salamanders with fresh bedding and fed each salamander approximately 20 wingless fruit flies Drosophila melanogaster once per week. Throughout the duration of the experiment, the salamanders were housed in an environmental chamber at $18.5^{\circ} \mathrm{C}$ with a 12:12 light:dark photoperiod. Exposure to $\mathrm{Bd}$ occurred within 2 to $4 \mathrm{wk}$ after the salamanders were collected.

In Expt 1, we were interested in obtaining the rate at which salamanders could clear $B d$ and thus this experiment utilized only $B d$-exposed salamanders. In Expt 2, we were interested in comparing feeding behavior of $B d$-infected and non-infected salamanders, so we randomly assigned the salamanders into 1 of 2 treatment groups: $B d$-exposed ( $\mathrm{n}=12$ ) and control $(\mathrm{n}=12)$. We then weighed the salamanders (to the nearest $0.01 \mathrm{~g}$ ) prior to being exposed to the appropriate $B d$ treatment to confirm that the 2 treatment groups did not differ in their mass (because larger salamanders might generally eat more food than smaller salamanders). At the start of Expt 2, the masses of the salamanders in each treatment group were similar (mean $\pm \mathrm{SE}, B d$-exposed: $0.70 \mathrm{~g} \pm 0.08$, control: $0.74 \mathrm{~g} \pm$ 0.05).

\section{Bd exposure}

Our $B d$ exposure protocols were similar for both experiments. Bd (JEL 660/JS OH-1, isolated from an infected amphibian in Ohio, USA) was grown in the laboratory in $1 \%$ tryptone broth. For salamanders in the $B d$-exposed treatment, we pipetted a $5.0 \mathrm{ml}$ dose of $B d$ that contained approximately $7 \times 10^{5}$ zoospores onto the dorsal surface of each salamander. Excess broth and zoospores were allowed to trickle onto the bedding of the salamander's container. In Expt 2, we also exposed salamanders from the control treatment to $5.0 \mathrm{ml}$ of $1 \%$ tryptone broth that did not contain any $B d$ zoospores. In both experiments, we transferred salamanders from the containers in which they were exposed to $B d$ (or a tryptone control) to new containers with fresh bedding (as described above) after $24 \mathrm{~h}$.

\section{Expt 1: $B d$ clearance}

Throughout the $28 \mathrm{~d}$ experiment, salamanders were maintained in the laboratory and exposed to $B d$ as described above. We swabbed the dorsal surface, including the tail, of each salamander 10 times with a sterile fine-tipped swab (product MW113; Advantage Bundling) on Days 5, 10, 17, and 28 post exposure. We stored the swabs at $-20^{\circ} \mathrm{C}$ until further analysis and assessed the infection burden via quantitative polymerase chain reaction (qPCR; described below). Throughout this experiment, we monitored salamanders daily for mortality.

\section{Expt 2: Salamander feeding and mass change}

We observed salamander feeding behavior on Days 7, 14, and 28 post exposure. Prior to each behavioral observation, we randomized the order of the observations so that we did not confound treatment with time of day. The feeding observations were conducted blind such that the researchers did not know the treatment of the salamander that they were observing. The order of the observations was randomized prior to the start of each trial date, and the researchers did not necessarily observe the same salamander on each of the 3 trial dates.

Immediately prior to each observation, an individual salamander was removed from its container and placed in a $25 \mathrm{~mm}$ deep $\times 140 \mathrm{~mm}$ diameter Petri dish (hereafter 'behavioral arena'). After a 3 min acclimation period, a researcher placed 10 wingless fruit flies in the behavioral arena, marking the start of a $10 \mathrm{~min}$ trial. During the behavioral trial, we recorded the number of attacks (successful and unsuccessful) made on each fruit fly. Immediately following the behavioral trial, we weighed each salamander (to the nearest $0.01 \mathrm{~g}$ ) and swabbed its dorsal surface, including the tail, 10 times with a sterile fine-tipped swab (product MW113; Advantage Bundling). We stored the swabs at $-20^{\circ} \mathrm{C}$ until further analysis and assessed the infection burden via qPCR (described below). Throughout this experiment, we monitored salamanders daily for mortality.

To prevent cross-contamination with $B d$ or $B d$ DNA, experimenters used a different pair of nitrile gloves whenever they handled a salamander. In addition, we used a different behavioral arena for each salamander. Throughout the experiment, we sterilized all of the equipment by either soaking it in $10 \%$ bleach or placing it in an autoclave (Johnson et al. 2003). 


\section{Detection of $B d$}

The number of genome equivalents on each swab was measured using qPCR on an Applied Biosystems Step One Real-time PCR System. Our DNA extractions and qPCR analyses followed the methods of Boyle et al. (2004) and those modified by Hyatt et al. (2007). Test samples were run singly instead of in triplicate to control costs (Kriger et al. 2006). We added TaqMan® Exogenous Internal Positive Control (Exo IPC) Reagents (Applied Biosystems) to every reaction well to assess inhibition of the PCR reaction (Hyatt et al. 2007). The Exo IPC system uses a standardized concentration of an artificial DNA sequence that is added to each reaction well with its own set of primers and a separate fluorescent probe. The strength of this reaction is used to assess overall reaction inhibition.

We considered infection intensity as the number of $B d$ zoospore equivalents per sample. Zoospore equivalents were calculated by multiplying the genome equivalent values generated by the qPCR assay by 80, which accounts for the 80-fold dilution of DNA from the swabs during extraction and qPCR preparation. We considered a sample $B d$ positive when zoospore equivalents were $\geq 1$.

\section{Statistical analyses}

For Expt 1, we used a linear mixed-effects model ( $\mathrm{R}$ statistical software, package: 'Ime4', function 'Imer') to test whether $B d$ abundance ( $\log [B d$ infection +1$]$, including animals with a zero infection) changed throughout the duration of the experiment as measured on the 4 swab dates. In this analysis, we nested salamander within trial to account for the repeated sampling of each salamander. We assessed significant differences $(p<0.05)$ using the 'Anova' function in the 'car' package in R statistical software.

For Expt 2, we conducted 2 separate analyses to test how $B d$ affected salamander feeding. In our first analysis, we used a generalized linear mixed-effects model (R statistical software, package: 'Ime4', function: 'glmer') with a Poisson error distribution to test for the main and interactive effects of treatment $(B d-$ exposed, control) and behavioral observation (Days 7,14 , and 28) on the number of attacks that each salamander made on fruit flies. In this analysis, we nested salamander within trial to account for the repeated observations of each salamander. We also used salamander mass as a covariate in this analysis. In our second analysis, we used a generalized linear mixed-effects model (R statistical software, package: 'Ime4', function: 'glmer') with a binomial error distribution to test for the main and interactive effects of treatment ( $B d$-exposed, control) and behavioral observation (Days 7, 14, and 28) on the number of successful captures that each salamander made on fruit flies. To do this, we converted our dataset into a binomial dataset such that each of the 10 flies was given a value of 'captured' or 'not captured.' In this analysis, we nested fly within trial, which was nested within salamander. As with our first statistical model, we used salamander mass as a covariate. We assessed significant differences $(p<0.05)$ in both statistical models using the 'Anova' function in the 'car' package in $\mathrm{R}$.

Next, we used a linear model to test whether $B d$-exposed and control salamanders differed in the percentage of mass change by the end of the experiment. We treated pathogen treatment as a categorical predictor and arcsine transformed our percentage data. We conducted this analysis using the ' $1 \mathrm{~m}$ ' function and assessed significant differences $(\mathrm{p}<0.05)$ using the 'Anova' function in the 'car' package in R statistical software.

\section{RESULTS}

\section{Expt 1: Bd clearance}

There was no salamander mortality in this experiment. $B d$ abundance changed significantly across the 4 swab dates $\left(\chi^{2}{ }_{3}=165.99, p<0.001\right)$. All of the salamanders tested positive for $B d$ on Day 5 and had an average $B d$ abundance of $23446.44\left( \pm 7361.47 \mathrm{SE}_{\text {; }}\right.$ Fig. 1). By Day 17, $B d$ prevalence decreased to $38 \%$, and the average $B d$ abundance was $174.61( \pm 69.71$; Fig. 1). Upon termination of the experiment on Day 28 , none of the salamanders tested positive for $B d$ (Fig. 1).

\section{Expt 2: Salamander feeding and mass change}

Salamanders that were infected with $B d$ attacked fruit flies significantly more often than non-exposed salamanders $\left(\chi_{1}^{2}=3.941, p=0.047 ;\right.$ Fig. $\left.2 \mathrm{~A}\right)$. The variables of trial and mass, as well as the interaction between pathogen treatment and trial, did not vary between $B d$-exposed and non-exposed salamanders (trial: $\chi^{2}{ }_{2}=4.621, \mathrm{p}=0.099$; treatment $\times$ trial: $\chi^{2}{ }_{2}=$ 1.249, $\mathrm{p}=0.536$; mass: $\left.\chi^{2}{ }_{1}=1.821, \mathrm{p}=0.177\right)$. We observed a trend suggesting an increase in the num- 


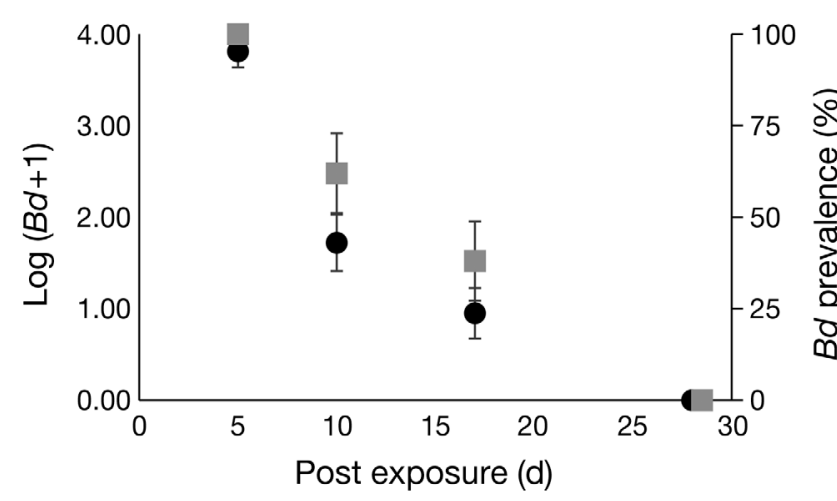

Fig. 1. Batrachochytrium dendrobatidis $(B d)$ abundance (left $y$-axis, circles) and prevalence (right $y$-axis, squares) in eastern red-backed salamanders Plethodon cinereus throughout the experiment. Error bars indicate $1 \mathrm{SE}$. Bd was detected using $\mathrm{qPCR}$, and swabs of the salamanders were obtained on Days 5, 10, 17, and 28 post exposure. By Day 17, the $B d$ abundance and prevalence decreased by more than $50 \%$ of their original values. All salamanders cleared their $B d$ infection by Day 28

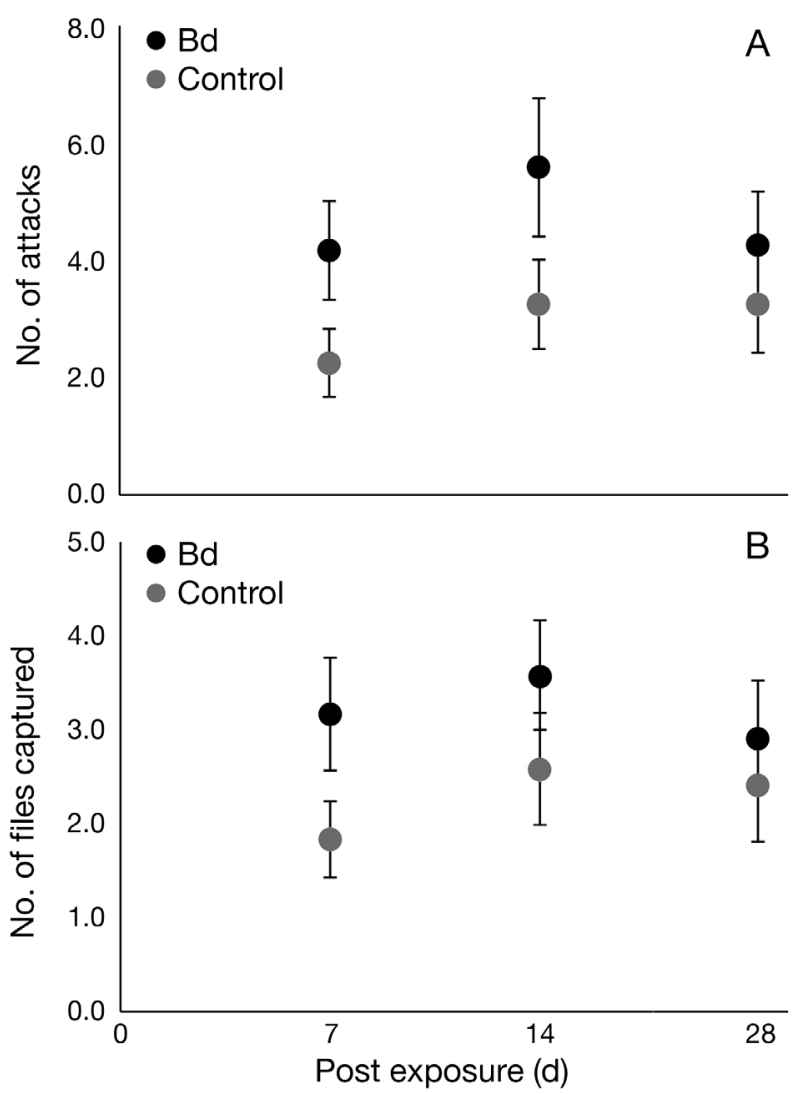

Fig. 2. Treatment differences in the number of fruit flies Drosophila melanogaster (A) attacked and (B) captured between eastern red-backed salamanders Plethodon cinereus exposed and non-exposed to Batrachochytrium dendrobatidis $(B d)$. Salamanders exposed to $B d$ attacked significantly more flies $(\mathrm{p}=0.047)$ and tended to capture more flies $(\mathrm{p}=$ 0.096) compared to non-exposed salamanders, irrespective of the date of the behavioral trial. Error bars indicate $1 \mathrm{SE}$ ber of successful captures as a function of pathogen treatment and trial (Fig. 2B); however, these results were all non-significant (treatment: $\chi^{2}{ }_{1}=2.763, \mathrm{p}=$ 0.096; trial: $\chi_{2}^{2}=2.255, \mathrm{p}=0.390$; treatment $\times$ trial: $\chi^{2}{ }_{2}=1.320, p=0.573$; mass: $\chi^{2}{ }_{1}=0.642, p=0.423$ ).

In addition to the effects of $B d$ on feeding, we found that $B d$ infection did not affect survival $(100 \%$ of the salamanders survived throughout the experiment), and $B d$ infection did not affect salamander growth. There was no difference in the percentage of mass change between $B d$-infected and non-infected salamanders when comparing $28 \mathrm{~d}$ mass to the preexperiment mass $\left(F_{1,22}=0.202, \mathrm{p}=0.658\right.$; Fig. 3$)$.

\section{DISCUSSION}

The results of our first experiment (Fig. 1) corroborate previous research demonstrating that individuals of the eastern red-backed salamander Plethodon cinereus are generally resistant to $B d$ and that they can clear their $B d$ infections within $28 \mathrm{~d}$ (Becker \& Harris 2010) at a temperature that is thought to be optimal for $B d$ growth in culture (Piotrowski et al. 2004). In addition, in the second experiment, we found evidence that $B d$-infected salamanders increase their feeding activity (Fig. 2A) and tended to increase their food consumption (Fig. 2B) relative to non-infected salamanders.

Deploying an immune response is generally energetically demanding, and it frequently involves an increase in an organism's resting metabolic rate (Sheldon \& Verhulst 1996, Lochmiller \& Deerenberg

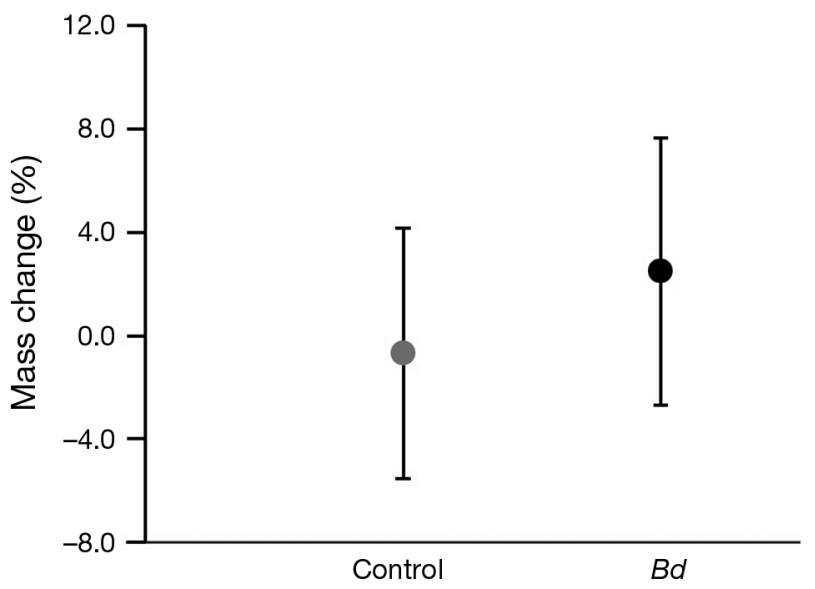

Fig. 3. Percentage of mass change (Day 0 versus Day 28 mass) between eastern red-backed salamanders Plethodon cinereus exposed and non-exposed to Batrachochytrium dendrobatidis $(B d)$. Error bars indicate 1 SE. There was no significant difference between the 2 treatment groups $(\mathrm{p}=0.658)$ 
2000). One way to reduce the energy losses from the redistribution of resources from anabolic daily processes (e.g. growth and reproduction) to immune deployment is to increase feeding activity. Although some studies have shown that infected hosts generally decrease their food intake (reviewed by Lochmiller \& Deerenberg 2000), recent research has demonstrated that infected hosts can sometimes shift their feeding behavior so that they offset the costs associated with immune activation (Lee et al. 2006, 2008). Our result that $B d$-infected salamanders attacked more flies than non-infected salamanders (Fig. 2A) and tended to capture more flies (Fig. 2B) supports the hypothesis that increasing feeding activity might limit the extent of the nutritional deficits associated with immune deployment. These results are also similar to a recent study that demonstrated that increased dietary protein enhanced $B d$ resistance in anuran tadpoles (Venesky et al. 2012). Understanding the energetic costs of immune maintenance and deployment in amphibians that are generally resistant versus those that succumb to $B d$ would help put these findings into a broader context and should be a focal point of future research in amphibian disease ecology.

Determining the exact immune parameters that confer $B d$ resistance in $P$. cinereus was beyond the scope of our study. For $P$. cinereus (and other species of amphibians), commensal skin bacteria work in association with components of the innate immune system (e.g. antimicrobial peptides) to reduce the infection burden of cutaneous pathogens such as $B d$ (Myers et al. 2012, Colombo et al. 2015). Recent research has highlighted the fact that the cutaneous microbial community found on some species of amphibians can minimize $B d$-induced mortality and other sub-lethal effects of chytridiomycosis (reviewed by Bletz et al. 2013). For instance, in $P$. cinereus infected with $B d$, salamanders with intact microbial communities suffered lower mass loss than salamanders stripped of their cutaneous bacteria (Becker \& Harris 2010). However, the removal of commensal skin microbes does not appear to affect $B d$ infection intensity, and salamanders with reduced skin microbiota can still clear their $B d$ infections within $28 \mathrm{~d}$ after exposure (Becker \& Harris 2010). The findings of Becker \& Harris (2010) suggest that components of the innate immune system can clear $B d$ infections independent of the skin microbiota. It is our hypothesis that salamander resistance is driven, in part, by antimicrobial peptides, which are known to confer resistance to $B d$ in some species (Woodhams et al. 2007). Antimicrobial peptide synthesis in vertebrates is either constitutive or inducible (Ganz 2003) and is presumably costly; increasing feeding activity during these times is a plausible host response that could offset the costs associated with this type of immune activity.

We also found that $100 \%$ of the $B d$-infected salamanders cleared their infections while experiencing a similar change in mass compared to the nonexposed salamanders (Fig. 3). This finding is important because it further supports our hypothesis that increased feeding activity of $B d$-infected salamanders relative to non-infected salamanders can be used to reduce any nutritional deficits that resulted from immune activity. Based on this logic, $B d$-infected and food-deprived salamanders should not clear their infections as quickly and should exhibit mortality compared to $B d$-infected salamanders that are given higher quantities of food. Alternatively, the immune defenses might not be costly enough in this species to affect mass because the infections are cleared in such a short duration (Fig. 1). Future experiments that test these hypotheses would help elucidate how food quantity relates to susceptibility to $B d$.

Unlike most amphibian species which exhibit stereotypical pathologies during chytridiomycosis (e.g. mass loss, inappetence, lethargy), we found that $B d$-infected $P$. cinereus are generally resistant to $B d$ and cleared moderate infection levels within $28 \mathrm{~d}$ post exposure. During the experiment, $B d$-infected salamanders generally increased their feeding activity compared to non-infected salamanders, and they did not lose any mass during the course of an infection. Although we did not detect a significant interaction between pathogen treatment and time, it appears that the significant main effect of pathogen treatment is being driven primarily by salamander feeding responses earlier in the experiment compared to later in the experiment (i.e. Day 7 versus Day 28, as indicated by the error bars in Fig. 2). Although resistance to parasites is generally costly, our results suggest that increased feeding might help $B d$-infected salamanders minimize the costs of an effective immune response. These results provide an opportunity to improve our understanding of the relationship between host condition and $B d$ resistance and offer hope for amphibian management programs.

Although $B d$ is widely regarded as one of the deadliest pathogens on the planet (Rohr et al. 2008), not all amphibians are equally susceptible to $B d$ (Searle et al. 2011b), and differences in host resistance are particularly important because this variation can 
affect disease outcomes in amphibian communities (Searle et al. 2011a, Venesky et al. 2014). Our results, coupled with the evidence that field-collected plethodontid salamanders rarely test positive for $B d$ from natural environments (Muletz et al. 2014), suggest that Plethodon spp. have traits that promote resistance to $B d$. From an ecological perspective, knowing whether Plethodon spp. generally dilute disease risk for other amphibian species might help us understand regional patterns of $B d$. The incidence of $B d$ in the US is generally low in regions with high plethodontid salamander diversity (Olson et al. 2013), which supports the possibility that Plethodon spp. generally dilute $B d$ risk. Nonetheless, many other biotic and abiotic factors that are known to affect the distribution of $B d$ (Liu et al. 2013, Venesky et al. 2014) could be correlated with the geographic distribution of Plethodon spp., further emphasizing the need to understand whether salamanders dilute the risk of chytridiomycosis in natural settings.

Acknowledgements. We thank Jason Rohr for discussions on statistical analyses. This research was supported by Allegheny College and the Biology Department. The salamanders used in this study were collected under a scientific collection permit from the Pennsylvania State Fish and Boat Commission (to M.D.V.). The Allegheny College Animal Research Committee oversees all animal research conducted at Allegheny College. All applicable institutional and/or national guidelines for the care and use of animals were followed. We declare that we have no conflicts of interest.

\section{LITERATURE CITED}

Ardia DR, Gantz JE, Schneider BC, Strebel S (2012) Costs of immunity in insects: an induced immune response increases metabolic rate and decreases antimicrobial activity. Funct Ecol 26:732-739

> Becker MH, Harris RN (2010) Cutaneous bacteria of the redback salamander prevent morbidity associated with a lethal disease. PLoS ONE 5:e10957

Bletz MC, Loudon AH, Becker MH, Bell SC, Woodhams DC, Minbiole KPC, Harris RN (2013) Mitigating amphibian chytridiomycosis with bioaugmentation: characteristics of effective probiotics and strategies for their selection and use. Ecol Lett 16:807-820

Boyle DG, Boyle DB, Olsen V, Morgan JAT, Hyatt AD (2004) Rapid quantitative detection of chytridiomycosis (Batrachochytrium dendrobatidis) in amphibian samples using real-time Taqman PCR assay. Dis Aquat Org 60:141-148

$>$ Brzek P, Konarzewski M (2007) Relationship between avian growth rate and immune response depends on food availability. J Exp Biol 210:2361-2367

> Colombo BM, Scalvenzi T, Benlamara S, Pollet N (2015) Microbiota and mucosal immunity in amphibians. Front Immunol 6:111

de Roode JC, Lefevre T, Hunter MD (2013) Self-medication in animals. Science 340:150-151
Diamond SE, Kingsolver JG (2011) Host plant quality, selection history and trade-offs shape the immune responses of Manduca sexta. Proc R Soc Lond B Biol Sci 278: 289-297

> Ellison AR, Tunstall T, DiRenzo GV, Hughey MC and others (2015) More than skin deep: functional genomic basis for resistance to amphibian chytridiomycosis. Genome Biol Evol 7:286-298

- Fites JS, Ramsey JP, Holden WM, Collier SP and others (2013) The invasive chytrid fungus of amphibians paralyzes lymphocyte responses. Science 342:366-369

> Ganz T (2003) The role of antimicrobial peptides in innate immunity. Integr Comp Biol 43:300-304

> Gasparini J, Roulin A, Gill VA, Hatch SA, Boulinier T (2006) In kittiwakes food availability partially explains the seasonal decline in humoral immunocompetence. Funct Ecol 20:457-463

Gegear RJ, Otterstatter MC, Thomson JD (2006) Bumblebee foragers infected by a gut parasite have an impaired ability to utilize floral information. Proc R Soc Lond B Biol Sci 273:1073-1078

> Hasselquist D, Nilsson JA (2012) Physiological mechanisms mediating costs of immune responses: What can we learn from studies of birds? Anim Behav 83:1303-1312

> Hyatt AD, Boyle DG, Olsen V, Boyle DB and others (2007) Diagnostic assays and sampling protocols for the detection of Batrachochytrium dendrobatidis. Dis Aquat Org 73:175-192

Johnson RW (2002) The concept of sickness behavior: a brief chronological account of four key discoveries. Vet Immunol Immunopathol 87:443-450

Johnson ML, Berger L, Philips L, Speare R (2003) Fungicidal effects of chemical disinfectants, UV light, desiccation and heat on the amphibian chytrid Batrachochytrium dendrobatidis. Dis Aquat Org 57:255-260

> Kriger KM, Hero JM, Ashton KJ (2006) Cost efficiency in the detection of chytridiomycosis using PCR assay. Dis Aquat Org 71:149-154

Lee KP, Cory JS, Wilson K, Raubenheimer D, Simpson SJ (2006) Flexible diet choice offsets protein costs of pathogen resistance in a caterpillar. Proc R Soc Lond B Biol Sci 273:823-829

> Lee KP, Simpson SJ, Wilson K (2008) Dietary protein-quality influences melanization and immune function in an insect. Funct Ecol 22:1052-1061

Liu X, Rohr JR, Li YM (2013) Climate, vegetation, introduced hosts and trade shape a global wildlife pandemic. Proc R Soc Lond B Biol Sci 280:20122506

Lochmiller RL, Deerenberg C (2000) Trade-offs in evolutionary immunology: Just what is the cost of immunity? Oikos 88:87-98

Martin LB, Weil ZM, Nelson RJ (2008) Seasonal changes in vertebrate immune activity: mediation by physiological trade-offs. Philos Trans R Soc Lond B Biol Sci 363:321-339

> McKean KA, Yourth CP, Lazzaro BP, Clark AG (2008) The evolutionary costs of immunological maintenance and deployment. BMC Evol Biol 8:76

- McMahon TA, Sears BF, Venesky MD, Bessler SM and others (2014) Amphibians acquire resistance to live and dead fungus overcoming fungal immunosupression. Nature 511:224-227

Muletz C, Caruso NM, Fleischer RC, McDiarmid RW, Lips KR (2014) Unexpected rarity of the pathogen Batrachochytrium dendrobatidis in Appalachian Plethodon salamanders: 1957-2011. PLoS ONE 9:e103728 
Myers JM, Ramsey JP, Blackman AL, Nichols AE, Minbiole KP, Harris RN (2012) Synergistic inhibition of the lethal fungal pathogen Batrachochytrium dendrobatidis: the combined effect of symbiotic bacterial metabolites and antimicrobial peptides of the frog Rana muscosa. J Chem Ecol 38:958-965

> Olson DH, Aanensen DM, Ronnenberg KL, Powell CI and others (2013) Mapping the global emergence of Batrachochytrium dendrobatidis, the amphibian chytrid fungus. PLoS ONE 8:e56802

Owen-Ashley NT, Wingfield JC (2006) Seasonal modulation of sickness behavior in free-living northwestern song sparrows (Melospiza melodia morphna). J Exp Biol 209: 3062-3070

Piotrowski JS, Annis SL, Longcore JE (2004) Physiology of Batrachochytrium dendrobatidis, a chytrid pathogen of amphibians. Mycologia 96:9-15

Povey S, Cotter SC, Simpson SJ, Lee KP, Wilson K (2009) Can the protein costs of bacterial resistance be offset by altered feeding behaviour? J Anim Ecol 78:437-446

Ramsey JP, Reinert LK, Harper LK, Woodhams DC, RollinsSmith LA (2010) Immune defenses against Batrachochytrium dendrobatidis, a fungus linked to global amphibian declines, in the South African clawed frog, Xenopus laevis. Infect Immun 78:3981-3992

Rohr JR, Raffel TR (2010) Linking global climate and temperature variability to widespread amphibian declines putatively caused by disease. Proc Natl Acad Sci USA 107:8269-8274

Rohr JR, Raffel TR, Romansic JM, McCallum H, Hudson PJ (2008) Evaluating the links between climate, disease spread, and amphibian declines. Proc Natl Acad Sci USA 105:17436-17441

Rollins-Smith LA, Reinert LK, Burrowes PA (2015) Coqui frogs persist with the deadly chytrid fungus despite a lack of defensive antimicrobial peptides. Dis Aquat Org 113:81-83

Schmid-Hempel P (2003) Variation in immune defence as a question of evolutionary ecology. Proc R Soc Lond B Biol Sci 270:357-366

Searle CL, Biga LM, Spatafora JW, Blaustein AR (2011a) A dilution effect in the emerging amphibian pathogen

Editorial responsibility: Louise Rollins-Smith,

Nashville, Tennessee, USA
Batrachochytrium dendrobatidis. Proc Natl Acad Sci USA 108:16322-16326

Searle CL, Gervasi SS, Hua J, Hammond JI, Relyea RA, Olson DH, Blaustein AR (2011b) Differential host susceptibility to Batrachochytrium dendrobatidis, an emerging amphibian pathogen. Conserv Biol 25:965-974

Sheldon BC, Verhulst S (1996) Ecological immunology: costly parasite defenses and trade-offs in evolutionary ecology. Trends Ecol Evol 11:317-321

> Thompson SN, Redak RA, Wang LW (2005) Host nutrition determines blood nutrient composition and mediates parasite developmental success: Manduca sexta L. parasitized by Cotesia congregata. J Exp Biol 208:625-635

> Tyler ER, Adams S, Mallon EB (2006) An immune response in the bumblebee, Bombus terrestris leads to increased food consumption. BMC Physiol 6:6

$>$ Venesky MD, Parris MJ, Storfer A (2009) Impacts of Batrachochytrium dendrobatidis infection on tadpole foraging performance. EcoHealth 6:565-575

> Venesky MD, Wilcoxen TE, Rensel MA, Rollins-Smith L, Kerby JL, Parris MJ (2012) Dietary protein restriction impairs growth, immunity, and disease resistance in southern leopard frog tadpoles. Oecologia 169:23-31

Venesky MD, Liu X, Sauer EL, Rohr JR (2014) Linking manipulative experiments to field data to test the dilution effect. J Anim Ecol 83:557-565

- Venesky MD, Hess A, DeMarchi JA, Weil A, Murone J, Hickerson CAM, Anthony CD (2015) Morph-specific differences in disease prevalence and pathogen-induced mortality in a terrestrial polymorphic salamander. J Zool (Lond) 295:279-285

> Voyles J, Rosenblum EB, Berger L (2011) Interactions between Batrachochytrium dendrobatidis and its amphibian hosts: a review of pathogenesis and immunity. Microbes Infect 13:25-32

Wake DB, Vredenburg VT (2008) Are we in the midst of the sixth mass extinction? A view from the world of amphibians. Proc Natl Acad Sci USA 105:11466-11473

Woodhams DC, Ardipradja K, Alford RA, Marantelli G, Reinert LK, Rollins-Smith L (2007) Resistance to chytridiomycosis varies among amphibian species and is correlated with skin peptide defenses. Anim Conserv 10:409-417

Submitted: June 10, 2015; Accepted: August 10, 2015

Proofs received from author(s): October 12, 2015 